\title{
Argumentação de Graduandos em Química sobre Questões Sociocientíficas em um Ambiente Virtual de Aprendizagem
}

\section{Undergraduate chemistry students' argumentation on socio-scientific issues in a virtual learning environment}

\author{
Nilcimar S. Souza, Patrícia F. O. Cabral e Salete L. Queiroz
}

\begin{abstract}
Resumo: Numerosos estudos destacam a importância da argumentação na aquisição do conhecimento científico e sugerem que a sua promoção deve ser fomentada em ambientes de ensino de ciências. O objetivo deste trabalho foi identificar como graduandos em química, agrupados em duplas, construíram argumentos durante a participação em uma atividade didática pautada na discussão de questões sociocientíficas. Os argumentos foram elaborados durante períodos de trabalho colaborativo assíncrono em um ambiente virtual de aprendizagem, denominado eduqui.info, no contexto de uma disciplina de comunicação científica. Dois quadros analíticos foram empregados para avaliar a qualidade da argumentação dos alunos: quadro analítico Rainbow (foco na natureza epistêmica das contribuições dos alunos durante a etapa de colaboração) e um quadro analítico estrutural (foco nas relações existentes entre a qualidade estrutural dos argumentos e a qualidade conceitual e qualidade de fundamentos).
\end{abstract}

Palavras-chave: argumentação colaborativa, questões sociocientíficas, estudo de casos.

\begin{abstract}
Numerous studies highlight the importance of argumentation in the acquisition of scientific knowledge and advocate that it should be reinforced in science classrooms. The purpose of this study was to identify how undergraduate chemistry students that participated in a specially designed instructional approach within a socioscientific issue construct arguments when working in pairs. The arguments were constructed during periods of asynchronous and collaborative work in a virtual learning environment named eduqui.info in the context of a scientific communication course. Two frameworks for evaluating the quality of students' argumentation were applied: Rainbow framework (the focus is on the epistemic nature of the contributions that students make during collaboration) and a structural framework (the focus is on the relationships between the structural quality of discourse episodes and the nature, conceptual quality, and grounds quality of constituent student contributions).
\end{abstract}

Keywords: collaborative argumentation, socioscientific issues, case studies.

\footnotetext{
Nilcimar dos Santos Souza (nilcimar@iqsc.usp.br), professor da Universidade Federal do Rio de Janeiro (UFRJ), é doutorando do Programa de Pós-Graduação em Química do Instituto de Química de São Carlos, Universidade de São Paulo (USP). São Carlos, SP - BR. Patrícia Fernanda de Oliveira Cabral (petycabral@ gmail.com), mestranda do Programa de Pós-Graduação em Química do Instituto de Química de São Carlos, USP, atuou como professora efetiva da rede estadual de ensino do estado de São Paulo. São Carlos, SP - BR. Salete Linhares Queiroz (salete@ iqsc.usp.br), professora do Instituto de Química de São Carlos, USP, coordena o Grupo de Pesquisa em Ensino de Química do Instituto de Química de São Carlos (GPEQSC). São Carlos, SP - BR. Recebido em 08/10/2014, aceito em 13/04/2015
} 
No âmbito da educação em ciências, diversas pesquisas têm sido desenvolvidas nos últimos anos a fim de investigar a construção de argumentos por parte dos alunos de distintos níveis de ensino (Santos, 2014; Kim et al., 2007; Jiménez-Aleixandre, 2014). A intensificação das pesquisas se sustenta, principalmente, na possibilidade de a prática argumentativa levá-los a uma compreensão mais adequada dos conceitos científicos e melhor entendimento sobre a própria natureza da construção do conhecimento científico (Erduran; Jiménez-Aleixandre, 2008). Movimento semelhante tem se observado com relação ao interesse pelo uso de aplicações baseadas na web para fins educacionais. Investigações dessa natureza buscam facilitar a interação entre os alunos por meio da utilização de sistemas de comunicação mediada por computador (Gijlers et al., 2013).

Considerando que os alunos de química no nível superior raramente são convidados a se posicionarem e desenvolverem argumentos para justificar suas posições (Queiroz; Sá, 2009), a elaboração e aplicação de atividades didáticas pautadas na Aprendizagem Colaborativa com Suporte Computacional (Computer Supported Collaborative Learning - CSCL) podem propiciar condições adequadas para a aquisição de habilidades argumentativas (Stahl et al., 2014). Assim, são criadas oportunidades para eles construírem conhecimentos enquanto argumentam em torno de um determinado tópico de forma colaborativa (Munneke et al., 2007), de modo que possam considerar diferentes pontos de vista, fazer questionamentos uns aos outros e alcançar um entendimento mais amplo e aprofundado sobre o tema em foco.

Nesse cenário, o presente trabalho tem como propósito investigar discussões colaborativas mantidas no fórum do ambiente virtual de ensino-aprendizagem eduqui.info (www. gpeqsc.com.br/eduquiinfo), a partir da resolução de problemas autênticos, apresentados a alunos de graduação em química no formato de casos investigativos (Sá et al., 2007; Sá; Queiroz, 2009). Mais especificamente, visa responder às seguintes questões: a) Em que medida as atividades didáticas apresentadas no fórum do eduqui.info favorecem a prática da argumentação? b) Qual a qualidade dos argumentos produzidos pelos alunos a partir da realização de tais atividades?

Para investigar a qualidade dos argumentos gerados pelos alunos, é feito uso de referenciais apropriados para as características e condições em que os dados foram por eles elaborados, ou seja, para a análise dos dados produzidos na argumentação colaborativa dialógica (fórum de discussão na forma de sentenças vinculadas a perguntas, respostas, comentários, opiniões etc.), utiliza-se o quadro analítico Rainbow (Baker et al., 2007) e o quadro analítico para codificação de argumentação científica dialógica de estudantes em fóruns de discussão assíncronos (Clark; Sampson, 2008) que, a nosso ver, complementam-se. Ambos foram idealizados tendo em vista a análise de debates estabelecidos em ambientes virtuais e estão descritos sucintamente no tópico Referenciais Metodológicos de Análise.

\section{Argumentação sobre questões sociocientíficas apresentadas no formato de estudo de casos}

A argumentação pode ser considerada como uma habilidade essencial ao ser humano, sendo utilizada em muitos domínios e em uma variedade de situações como um advogado em um tribunal, um cientista postulando uma nova teoria, um político defendendo sua candidatura ou um funcionário solicitando ao patrão um novo pacote de software para seu setor de trabalho (Scheuer et al., 2010). Nesses cenários e em muitos outros ocultos na vida profissional e cotidiana, o protagonista cita fatos importantes, argumenta a favor de conclusões derivadas de tais fatos, contraria as alegações dos outros de maneira fundamentada, utilizando plenamente seus poderes de persuasão (Scheuer et al., 2010).

Esse quadro mostra a relevância do ensino e da prática da argumentação em ambientes educacionais em diversos campos de atuação. De fato, nas últimas décadas, pesquisas apontam para a necessidade do desenvolvimento de estratégias pedagógicas que estimulem a capacidade argumentativa dos estudantes sobre questões científicas e sociocientíficas em todos os níveis de escolaridade (Queiroz; Sá, 2009; Jiménez-Aleixandre, 2014). Em particular, a abordagem de questões sociocientíficas, que abrangem dilemas sociais e controvérsias vinculadas à ciência, tem sido recomendada com distintos objetivos (Santos, 2014), dentre os quais se destaca o desenvolvimento da capacidade de tomada de decisão dos alunos frente a questões vinculadas à sua realidade (educação para a cidadania).

Nessa perspectiva, já há uma considerável produção apontando modos pelos quais se podem promover situações propícias ao desenvolvimento do discurso argumentativo sobre questões sociocientíficas no processo de ensino-aprendizagem de ciências. No nosso país, é digna de nota a abordagem de questões dessa natureza apresentadas no formato de estudo de casos, também denominados de casos investigativos. Estes se constituem como o centro de um método pautado na instrução pelo uso de narrativas sobre indivíduos enfrentando dilemas contidos em determinadas situações (Herreid, 2003). Colocado no cenário da narrativa, o aluno é incentivado, sobretudo, a ler, a se familiarizar com personagens, a compreender fatos, valores e contextos presentes, visando uma solução que, de modo geral, não é a única (Sá; Queiroz, 2009).

Até onde vai o nosso conhecimento, o primeiro trabalho publicado em revista indexada no contexto nacional no qual a argumentação sobre questões sociocientíficas foi promovida a partir da aplicação de estudos de casos, no âmbito do ensino de química, ocorreu em 2007 (Sá; Queiroz, 2007). Este trata da aplicação de proposta de ensino desenvolvida no nível superior, tendo sido exigido dos graduandos a resolução de casos investigativos e posterior argumentação sobre a melhor solução adotada. Os argumentos elaborados pelos graduandos foram analisados segundo o Modelo de Toulmin (2001). Desde 
então, as investigações sobre a temática se ampliaram e vários trabalhos foram reportados na perspectiva de considerar as relações estabelecidas entre a promoção da argumentação, o uso de casos investigativos e a abordagem de questões sociocientíficas (Brito; Sá, 2010; Souza; Queiroz, 2014; Sousa et al., 2012; Pazinato; Braibante, 2014), inclusive na educação básica.

As questões sociocientíficas, também referenciadas pela sigla SSI (oriunda do inglês Socioscientific Issues), que permeiam os casos, costumam ter implicações em um ou mais dos seguintes campos: biologia, sociologia, ética, política, economia e ambiente. Brito e Sá (2010), por exemplo, propuseram aos alunos a resolução de caso investigativo, de modo que se posicionassem, a favor ou contra, sobre a instalação de uma fábrica de biodiesel em uma determinada região e apresentassem seus pontos de vista em relação à situação posta. As resoluções foram defendidas pelos alunos com base em argumentos de natureza econômica, ambiental, social e científica.

A utilização do Caso das Macieiras da Serra, publicado nesta revista, segundo Sousa et al. (2012), permitiu a discussão dos seguintes assuntos, além de conteúdos disciplinares: feromônios e o método atrai-mata; viabilidade da utilização de inseticidas; impactos ambientais da utilização de inseticidas (água, solo). No caso em questão, um agricultor da serra gaúcha enfrenta problemas no cultivo das maçãs. Seu filho busca ajuda para solucionar o problema da plantação de seu pai. A problemática é narrada, no caso, inclusive com as características que as maçãs apresentam pela infestação da mosca causadora dos danos. A partir dos subsídios contidos no texto, os estudantes identificaram o problema e buscaram a solução em função dos impactos dela resultantes.

Com intuito de ampliar o leque de discussões sobre a temática e subsidiar a análise dos argumentos gerados a partir da resolução de casos sociocientíficos, Sá (2010) construiu o Modelo de Análise de Argumentação Aplicável a Processos de
Resolução de Questões Sociocientíficas. Este apresenta três perspectivas de análise: a primeira está relacionada com a natureza dos critérios considerados no processo de resolução dos casos (natureza social, ambiental, econômica, ética, científica etc.); a segunda está relacionada com os diferentes tipos de fontes de evidências empregados na elaboração de argumentos e explicitados como forma de garantir confiabilidade às informações fornecidas; e a terceira está relacionada às estratégias de aprendizagem empregadas na defesa de argumentos.

A ampliação de trabalhos referentes à argumentação sobre questões sociocientíficas apresentadas no formato de estudo de casos pode ocorrer ainda por meio da inserção de tecnologias de informação e comunicação ao contexto investigado. $\mathrm{O}$ uso de ambientes virtuais de ensino-aprendizagem ancorados em um modelo de CSCL, alvo de atenção do presente artigo, surge como uma possibilidade.

\section{Referenciais metodológicos de análise}

\section{Quadro Analítico Rainbow}

O Rainbow (Baker et al., 2007) se origina no projeto SCALE (Internet-based Intelligent Tool to Support Collaborative Argumentation-based Learning). Financiado pela Comunidade Europeia, seu principal objetivo é o desenvolvimento de ferramentas CSCL visando ao aprendizado baseado em atividades argumentativas, tais como a escrita de textos e a construção de diagramas argumentativos. O quadro foi desenvolvido como ferramenta para análise de discussões argumentativas e abarca sete categorias principais, definidas e exemplificadas na Tabela 1.

As sete categorias descritas nessa tabela dizem respeito às ações que não se relacionam de modo algum com a tarefa prescrita pelo professor (categoria 1) e as que se relacionam,

Tabela 1. Categorias do quadro analítico Rainbow (Baker et al., 2007).

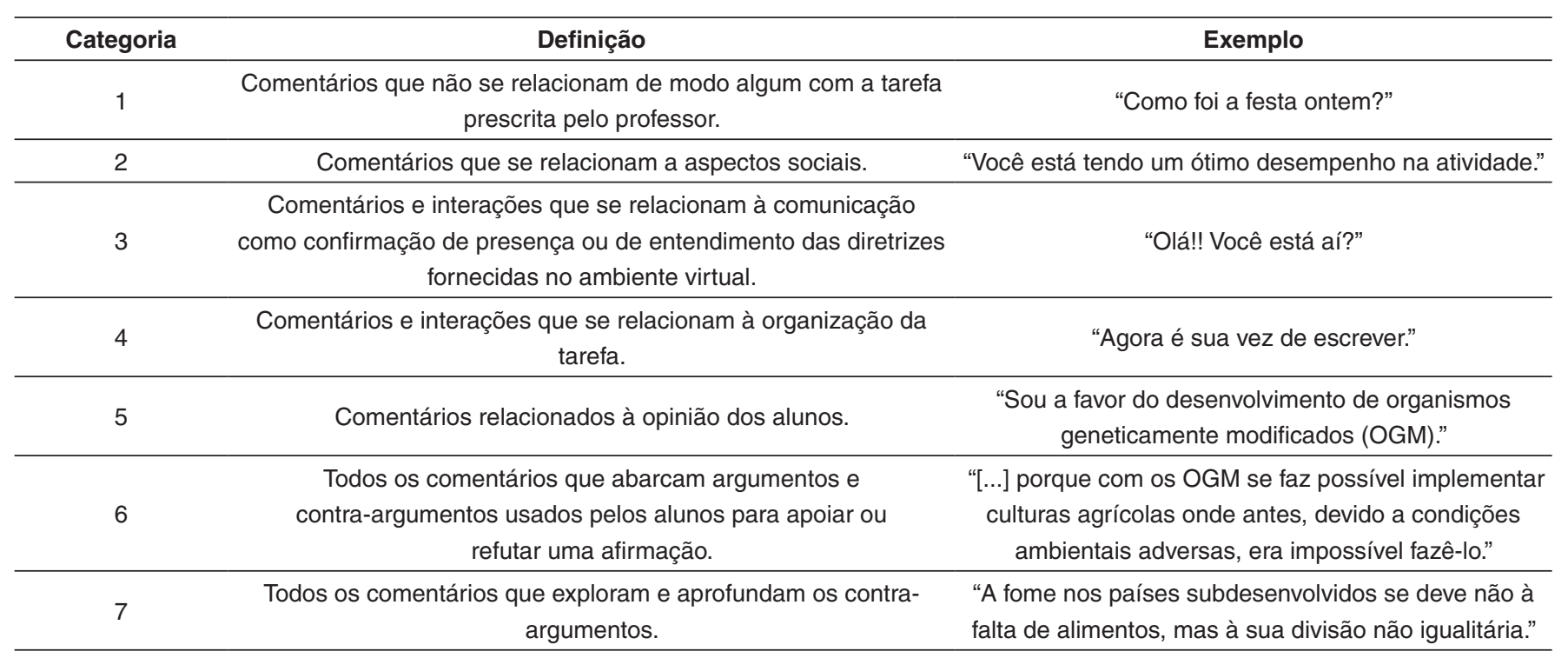


de algum modo, com esta (categorias 2-7). Dentre as categorias de 2-7, estão aquelas estreitamente vinculadas às solicitações presentes na tarefa (categorias 5-7), a que abarca aspectos sociais da interação (categoria 2), a que envolve o gerenciamento e a organização das interações (categoria 3) e a que compreende aspectos da organização da tarefa (categoria 4). Em outras palavras, a categoria 1 representa mensagens sem vínculo com a discussão; as categorias 2 e 3 representam as não focadas na atividade proposta; a categoria 4 representa as de organização da participação; e as últimas três categorias (5-7) incluem as com conteúdo argumentativo, sendo que a categoria 5 concerne à expressão de opiniões relacionadas ao tema em debate; a 6 expressa argumentos e contra-argumentos diretamente relacionados com a opinião ou solução defendida; e a 7 explora e aprofunda as conexões entre vários argumentos e contra-argumentos. Cabe destacar que qualquer mensagem pode ser classificada em uma ou mais categorias do quadro analítico. Por exemplo, pode ocorrer de em uma única mensagem o aluno emitir uma opinião (categoria 5), fornecer evidências e respaldos à opinião (categoria 6) e articular tais evidências com outros argumentos já colocados em discussão (categoria 7). No entanto, ao classificar uma mensagem em uma das categorias, não significa que automaticamente ela será abarcada por qualquer outra categoria.

O Rainbow evidencia as atividades realizadas no ambiente virtual, de forma a permitir que se aponte em que medida os alunos se engajam nas atividades argumentativas. A análise complementar, focada nas suas três últimas categorias, denominada na literatura de análise do aprofundamento e da amplitude do debate, indica a extensão com que estes exploraram o tópico em estudo com base na construção que fizeram de argumentos e contra-argumentos. Nessa análise, são considerados o número de tópicos e subtópicos mencionados no debate. De fato, na discussão de determinados assuntos, o espaço do debate é aprofundado e ampliado e os alunos argumentam com base em pontos de vista de diferentes atores (pesquisadores, cidadãos etc.) e em considerações sobre questões éticas, biológicas, políticas, econômicas etc.

A ocorrência de um maior número de mensagens classificadas nas categorias 5, 6 e 7 indica que a discussão se pautou majoritariamente em um debate argumentativo. Por outro lado, a recorrência de mensagens nas categorias 1-4, especialmente na categoria 1, indica ausência de conteúdo argumentativo e dedicação à organização da tarefa e em tergiversar sobre o tema.

O Rainbow, tal qual apresentado até o momento, é a proposta inicial de Baker et al. (2007). No entanto, os membros do projeto SCALE avançam nas análises com esse quadro. De acordo com Amelsvoort et al. (2007), quando os alunos se aprofundam em um tópico, eles não apenas dizem se algo é indicado ou não, mas fornecem exemplos, respaldam, contra-argumentam e refutam. Dessa forma, para uma investigação mais apurada das interações colaborativas, é necessário avançar a uma análise do aprofundamento e da amplitude das mensagens que expressam interações argumentativas (5-7). Para a análise do aprofundamento da argumentação, os autores consideram um sistema de pontuação de quatro níveis em ordem crescente de aprofundamento. No nível 1, a mensagem argumentativa inicia um argumento; no 2, fornece exemplo ou explicação de um argumento; no 3, inicia um respaldo ou refutação; e no 4, explicita relações entre diferentes argumentos. É desejável que os argumentos se concentrem nas categorias 3 e 4, expressando maior complexidade destes com a inclusão de respaldos, refutações e articulações entre eles.

Para a análise da amplitude, é considerada a natureza dos argumentos propostos nas mensagens. Em um contexto de casos investigativos que portam questões sociocientíficas, há a possibilidade de ocorrência de argumentos, por exemplo, de natureza social, científica, econômica, tecnológica, política, ambiental, ética etc. Espera-se que a solução do caso abarque argumentos de distintas naturezas.

Embora o uso do Rainbow seja potencialmente capaz de fornecer indícios sobre em que medida as atividades didáticas favorecem a prática da argumentação, assim como a amplitude com que os alunos incorporam à discussão diferentes naturezas de argumentos e se aprofundam nos tópicos, não permite a obtenção de indicativos sobre a adequação dos argumentos, do ponto de vista conceitual, a menos que seja incorporado outro referencial à análise. Nessa perspectiva, utilizamos um segundo referencial, o quadro analítico proposto por Clark e Sampson (2008).

\section{Quadro analítico proposto por Clark e Sampson}

O quadro analítico proposto por Clark e Sampson (2008) permite a análise da qualidade dos argumentos, considerando não apenas a sua estrutura, mas também a qualidade conceitual e os movimentos discursivos realizados na construção dos argumentos. Nessa perspectiva, comentários apresentados no fórum são classificados quanto ao movimento discursivo, à qualidade conceitual e à qualidade dos fundamentos. Esses três itens de avaliação estão nomeados conforme tradução literal do trabalho de Clark e Sampson (2008). No quadro analítico, caracteriza-se como fundamentos o seguinte conjunto de componentes do Modelo de Toulmin (2001): dados, justificativas e conhecimentos básicos ou garantias.

No que concerne à classificação dos movimentos discursivos, onze categorias são propostas conforme ilustra a Tabela 2. A primeira se relaciona com mensagens para enunciar argumentos. A segunda se relaciona com as mensagens que contra-argumentam um argumento enunciado. As duas seguintes incluem as possíveis refutações de um argumento. Outras duas são voltadas para as mudanças de argumentos e para os respaldos de uma mensagem. Há ainda duas destinadas aos tipos de esclarecimentos incluídos pelos alunos na discussão. Todas essas oito categorias representam mensagens com algum conteúdo argumentativo. Entretanto, as três seguintes dizem 
respeito àquelas mensagens sem qualquer conteúdo argumentativo. São elas: categorias de consulta sobre um significado, organização da participação e fora da tarefa.

A ocorrência de um maior número de mensagens classificadas entre as oito categorias que denotam algum conteúdo argumentativo indica que a discussão ocorreu majoritariamente sobre mensagens pertinentes à tarefa prescrita. De forma oposta, forte presença de mensagens classificadas nas três categorias que não estão vinculadas às mensagens argumentativas expressa uma discussão pobre em termos de uso da argumentação.

Após a classificação das mensagens quanto aos movimentos discursivos, aquelas indicadas entre as categorias que expressam conteúdo argumentativo são categorizadas com relação aos níveis de qualidade dos fundamentos na argumentação. Para a classificação das mensagens, em vez de apenas identificar a presença ou a ausência de fundamentos, Clark e Sampson (2008) propõem a sua classificação em níveis de fundamentos, definidos por uma escala ordinal após sucessão de respostas a uma sequência de decisões binárias. As classificações possíveis são: sem fundamentos (nível 0 de qualidade de fundamentos:); com apresentação apenas de explicações, sem evidências para suportá-las (nível 1); com apresentação de evidências (nível 2); com a articulação de múltiplas evidências (nível 3). A Figura 1 apresenta a sequência de decisões necessárias para classificação de uma mensagem a respeito de seu nível de qualidade de fundamentos.
Outra classificação efetuada sobre as mensagens de cunho argumentativo é com relação à sua qualidade conceitual que, assim como sua qualidade de fundamentos, é definida por Clark e Sampson (2008) em níveis de uma escala ordinal que varia de 0 a 3, determinada por uma sequência de respostas para decisões binárias (Figura 2). As questões colocadas para essas decisões baseiam-se na frequência de aspectos normativos, não normativos, multinormativos e transitórios nas mensagens, sendo afirmações normativas aquelas que traduzem o que faz e pensa a maioria dos membros de um coletivo social: nesse caso, a comunidade científica. As afirmações transitórias são aquelas compostas tanto por afirmações normativas como não normativas.

De posse das classificações de forma nominal e de forma ordinal, é possível avaliar como a discussão se desenvolveu quanto à qualidade dos fundamentos e à qualidade conceitual dos argumentos de natureza científica empregados.

\section{Percurso Metodológico}

A pesquisa foi desenvolvida na disciplina de Comunicação e Expressão em Linguagem Científica II, oferecida no segundo semestre do curso de bacharelado em química do Instituto de Química de São Carlos, Universidade de São Paulo (USP). A disciplina visa ao desenvolvimento de habilidades de

Tabela 2. Categorias do quadro analítico proposto por Clark e Sampson (2008).

\begin{tabular}{|c|c|}
\hline Movimento discursivo & Definição \\
\hline Enunciação de argumento & Uma mensagem inicial emitida por um aluno. \\
\hline Contra-argumento & $\begin{array}{l}\text { Uma mensagem emitida por um aluno que é diferente da mensagem anterior emitida por outro aluno. Essa categoria } \\
\text { se refere estritamente a asserções que não se vinculam com nenhum aspecto da tese ou do fundamento da } \\
\text { mensagem a qual responde. Em vez disso, oferecem uma interpretação inteiramente nova do fenômeno. }\end{array}$ \\
\hline $\begin{array}{l}\text { Refutação contra } \\
\text { fundamentos }\end{array}$ & $\begin{array}{l}\text { Um ataque contra ou discordância com os fundamentos usados por outro aluno para respaldar ou justificar sua } \\
\text { mensagem. }\end{array}$ \\
\hline Mudança de argumento & $\begin{array}{l}\text { Uma mensagem feita por um aluno que indica que houve (1) alterações na sua mensagem original; (2) mudanças } \\
\text { no seu ponto de vista; ou (3) concessões em resposta a argumentações ou refutações feitas por outro aluno. }\end{array}$ \\
\hline $\begin{array}{l}\text { Respaldo de um } \\
\text { argumento }\end{array}$ & $\begin{array}{l}\text { Uma mensagem usada para respaldar uma afirmação presente em uma argumentação ou uma refutação prévia. } \\
\text { Essa categoria inclui (1) concordância com uma mensagem; (2) reescrita de uma mensagem prévia; (3) adição de } \\
\text { fundamentos em respaldo a uma mensagem; ou (4) expansão de uma mensagem. }\end{array}$ \\
\hline $\begin{array}{l}\text { Esclarecimento de um } \\
\text { significado }\end{array}$ & $\begin{array}{l}\text { Uma mensagem realizada com o intuito de esclarecer outra emitida anteriormente (em contexto argumentativo). } 0 \\
\text { seu objetivo é tornar mais evidente o significado de uma mensagem em resposta a um questionamento ao invés } \\
\text { de questionar a exatidão desta. }\end{array}$ \\
\hline $\begin{array}{l}\text { Consulta sobre o } \\
\text { significado }\end{array}$ & $\begin{array}{l}\text { Uma mensagem que solicita esclarecimento com relação a outra dita anteriormente (ex: o que você quer dizer } \\
\text { quando afirma ou não entendo o que você está dizendo). }\end{array}$ \\
\hline $\begin{array}{l}\text { Organização da } \\
\text { participação }\end{array}$ & $\begin{array}{l}\text { Uma mensagem que (1) lembra outros alunos de participar da discussão; (2) questiona outros alunos por feedback } \\
\text { para a discussão; (3) possui um aspecto metaorganizacional (ex: todos vocês concordam?); (4) tenta mudar a forma } \\
\text { como outros estão participando da discussão. }\end{array}$ \\
\hline Fora da tarefa & Mensagens que não se relacionam ao assunto da tarefa (ex: que belo corte de cabelo!). \\
\hline
\end{tabular}




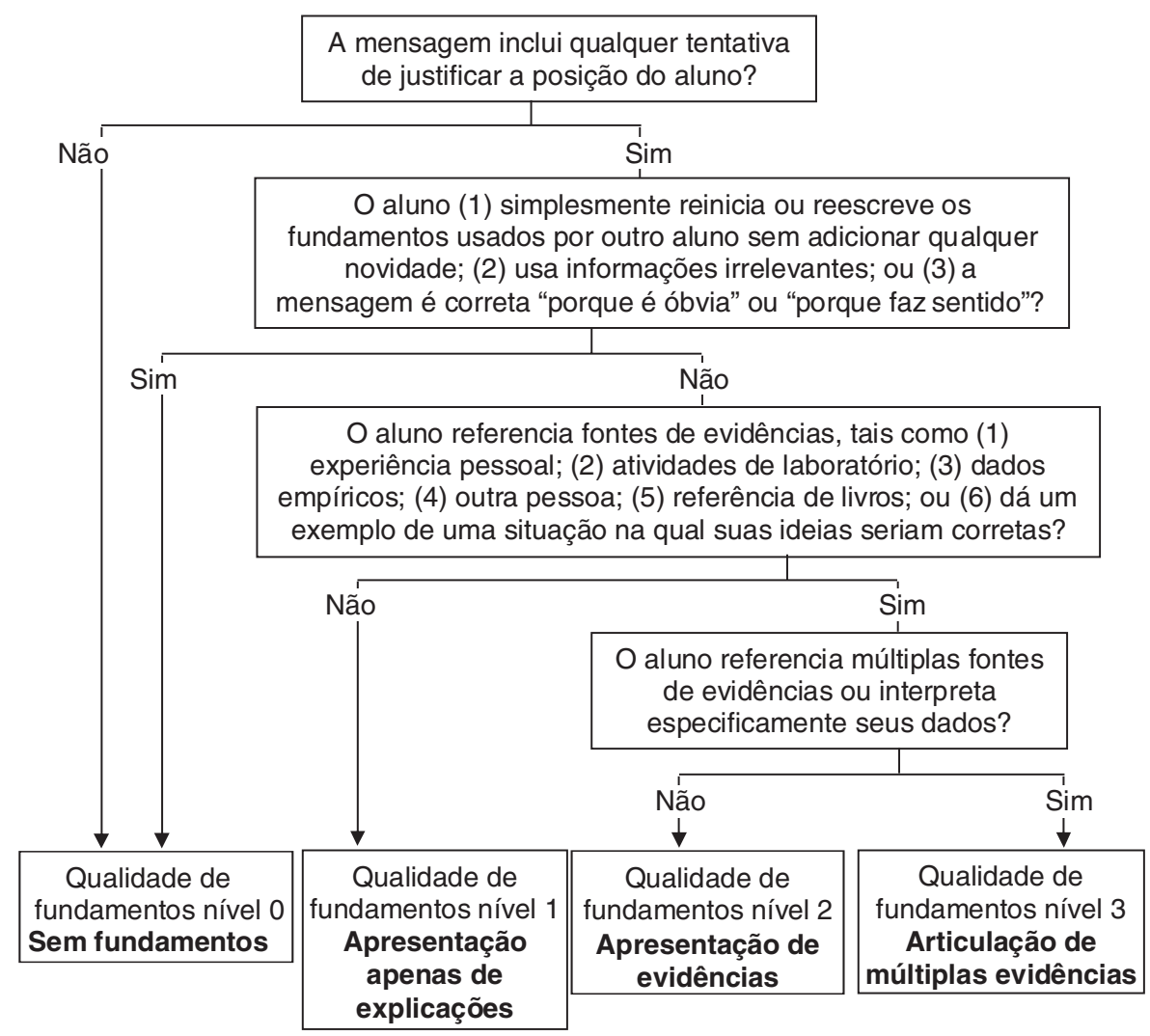

Figura 1. Esquema para classificação de mensagens quanto à qualidade de fundamentos (Clark; Sampson, 2008).

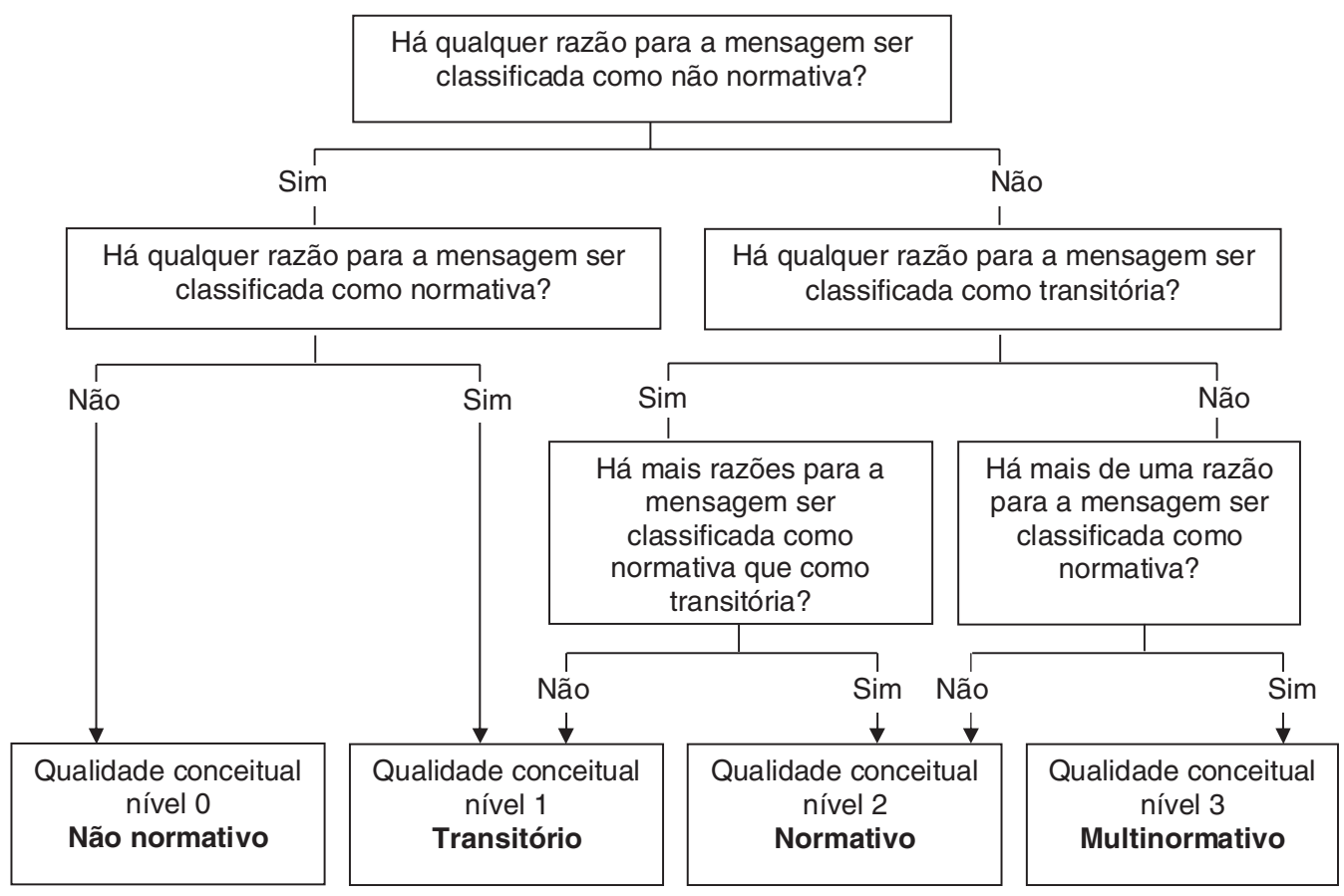

Figura 2. Esquema para classificação de mensagens quanto à qualidade conceitual (Clark; Sampson, 2008).

comunicação oral e escrita, sendo a turma em análise constituída de 23 alunos, que foram divididos em três grupos: um de dez componentes, outro com sete e o último com seis. Cada grupo foi convidado a solucionar um dos seguintes casos investigativos de caráter sociocientífico disponibilizados no eduqui. info: Dê a Cipreste algo que preste; Arquivo X; e $O$ silêncio das abelhas. Os resultados da análise das discussões travadas pelos alunos na busca de solução para o primeiro deles (Figura 3), de autoria de Fernando de Oliveira e Rafael Mario Vichietti, são abordados neste trabalho. 


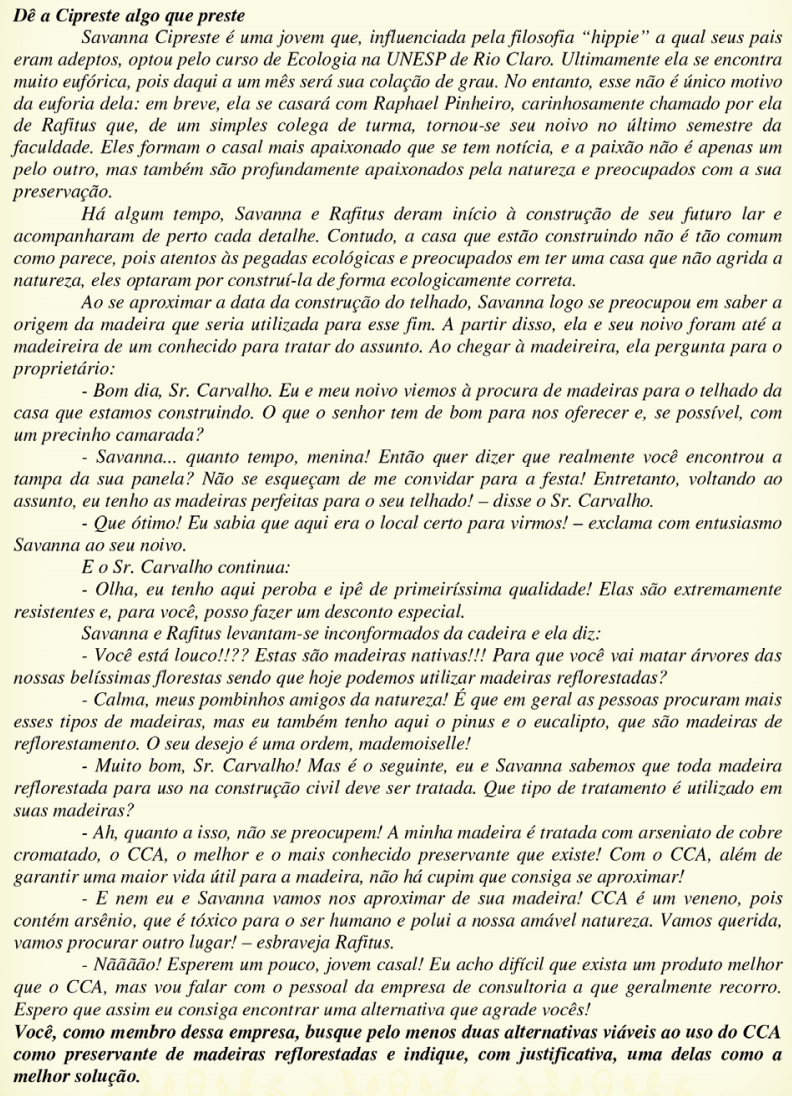

Figura 3. Caso Dê a Cipreste algo que preste.

Inicialmente, os dez alunos leram o referido caso, uma narrativa a respeito de um casal de noivos, Savanna Cipreste e Raphael Pinheiro, que se conheceram enquanto cursavam faculdade de Ecologia. Após se formarem, começaram a se preparar para o casamento e estavam construindo uma casa. Durante a construção do telhado, foram a uma madeireira comprar os materiais necessários. Lá, o proprietário lhes ofereceu madeiras nativas. Após a imediata recusa dos noivos, o proprietário sugeriu madeiras de reflorestamento como, por exemplo, pinus e eucalipto, tratadas com arseniato de cobre cromatado (CCA). Novamente a oferta foi prontamente descartada pelo casal, que alegou ser o arsênio tóxico não só aos insetos como aos moradores da casa. Diante do problema, os alunos, colocados no papel de funcionários de uma empresa de consultoria, deveriam propor a melhor solução para o caso e argumentar a seu favor. A resposta deveria ser elaborada textualmente em uma ferramenta específica do eduqui.info (etapa 1 da aplicação da proposta de ensino).

De posse da produção textual individual dos dez alunos na etapa 1, o professor formou cinco duplas (CIP1, CIP2, CIP3, CIP4, CIP5), de maneira que os membros apresentassem visões opostas acerca da melhor solução para o caso. As duplas trabalharam no fórum do eduqui.info e cada aluno teve de fornecer argumentos favoráveis à sua solução até que construíssem colaborativamente a resposta referente à melhor solução para o caso (etapa 2). Durante a colaboração, os alunos podiam acessar a solução do seu parceiro. Na última etapa, outra vez de forma individual, cada um produziu nova solução textual no eduqui. info (etapa 3). A realização das três etapas durou seis semanas com duas horas letivas em cada uma delas.

As mensagens produzidas no fórum foram classificadas pelas categorias do Rainbow e pelas categorias de movimento discursivo do quadro analítico proposto por Clark e Sampson (2008). Em seguida, aquelas mensagens compreendidas entre as categorias que expressam conteúdo argumentativo por esse quadro foram avaliadas quanto à amplitude e extensão do argumento. Já as mensagens classificadas entre as categorias argumentativas de Clark e Sampson (2008) foram investigadas quanto à qualidade dos fundamentos empregados e à qualidade conceitual. Portanto, a análise foi conduzida no sentido de empregar tais referenciais ao contexto específico da pesquisa aqui apresentada, sem reconstruções ou adaptações destes.

\section{Resultados e Discussão}

Nesta seção, analisamos as discussões efetuadas no fórum pelas duplas que solucionaram o caso Dê a Cipreste algo que preste. Inicialmente, investigamos as discussões a partir do Rainbow com o propósito de identificar o total de mensagens classificadas entre as categorias que denotam conteúdo argumentativo (5-7) e as que não expressam tal conteúdo (1-4).

Durante a etapa de análise da pesquisa, todos os estudos de caso trabalhados com alunos receberam uma avaliação prévia orientada pelos referenciais de Clark e Sampson (2008) e Baker et al. (2007). Os percentuais médios de mensagens classificadas pelos diversos aspectos avaliados forneceram indicativos que permitiram o estabelecimento de critérios para considerar as discussões como satisfatórias ou não em cada um desses aspectos.

Foi definida como satisfatória, do ponto de vista argumentativo, a discussão dos grupos que alcançaram pelo menos $80 \%$ de mensagens argumentativas, sendo $40 \%$ na categoria 7 e $40 \%$ nas categorias 5 e 6 . O desempenho das duplas que tenham alcançado os $80 \%$ de mensagens nas categorias 5-7, sem terem apresentado ao menos $40 \%$ na categoria 7 , concentrando suas afirmações, portanto, na 5 e na 6 , foi considerado regular. De igual forma, é regular a discussão que teve entre $40 \%$ e $79 \%$ de mensagens nas categorias 5-7. Duplas com menos de $40 \%$ nessas categorias tiveram o desempenho considerado insatisfatório.

Nas mensagens classificadas nas categorias 5-7, foi realizada a análise do aprofundamento e da amplitude da discussão. Com relação ao aprofundamento, consideramos satisfatória toda discussão em que ao menos a metade das mensagens classificadas como 5-7 pelo Rainbow estiveram nas categorias de níveis de aprofundamento mais elevada, 3 e 4. Consequentemente, consideramos insatisfatórias as discussões dos grupos que não alcançaram esse mínimo. Com relação à 
amplitude, consideramos satisfatória toda discussão cujo grupo conseguiu abordar o total de naturezas de argumento equivalente, no mínimo, à média alcançada por todos os demais grupos que solucionaram o mesmo estudo de caso. Consideramos insatisfatória toda discussão que apresentou total de naturezas de argumentos inferior à média dos grupos que solucionaram o mesmo caso.

Em seguida, analisamos as mensagens a partir do quadro analítico proposto por Clark e Sampson (2008) e consideramos satisfatórias todas as discussões que alcançaram pelo menos $80 \%$ de mensagens classificadas entre as oito categorias argumentativas. Classificamos na categoria regular discussões nas quais a produção argumentativa representa entre $40 \%$ e $79 \%$, e como insatisfatórias aquelas nas quais menos de $40 \%$ das mensagens foram argumentativas.

Nas mensagens classificadas nas categorias argumentativas, analisamos ainda a qualidade dos fundamentos dos argumentos. Quanto à análise dessa qualidade, consideramos satisfatórias as discussões nas quais pelo menos a metade das mensagens argumentativas foi classificada nos dois níveis mais elevados de qualidade de fundamentos, ou seja, os níveis 2 e 3 . Outra análise efetuada sobre as mensagens argumentativas foi a de qualidade conceitual. Esta, no caso específico do presente trabalho, foi realizada apenas com relação a mensagens pautadas em argumentos de natureza científica. Após a classificação das mensagens, consideramos satisfatórias aquelas que atingiram pelo menos a metade dos argumentos nas categorias de mais elevada qualidade conceitual, 2 e 3.

Conforme mencionado anteriormente, os alunos deveriam apresentar uma clara solução para o problema apresentado no caso - qual a madeira mais adequada para o telhado da casa de Cipreste? - e argumentar a seu favor. Na etapa anterior ao fórum, de produção de solução textual individual (etapa 1), os dez alunos solucionaram o caso expondo e defendendo suas soluções com argumentos que giraram em torno da adoção de três diferentes soluções: utilizar madeira de reflorestamento mantendo o CCA como preservante contra insetos xilófagos (quatro alunos); utilizar madeira de reflorestamento substituindo o CCA por borato de cobre cromatado (CCB) como preservante (quatro alunos); utilizar na estrutura do telhado polietileno de alta densidade, comercialmente denominado madeira plástica (dois alunos). As cinco duplas formadas produziram 67 mensagens, média de 13,4 por discussão. A Tabela 3 apresenta, para cada dupla, como os diversos posicionamentos e abordagens individuais de seus integrantes foram confrontados nos grupos e o total de mensagens produzidas em cada discussão.

Durante as discussões, os integrantes de CIP1, CIP2 e CIP3 debateram em torno dos pontos de vistas: manter o CCA ou substituí-lo pelo CCB? CIP1 finalizou a discussão considerando ser mais viável manter o CCA, pois além de possuir favorável relação custo-benefício comparado ao $\mathrm{CCB}$, há o fato de este também possuir alguma toxicidade e do arsênio do CCA não estar disponível em concentrações nocivas ao homem. CIP2 e CIP3, por outro lado, consideraram a melhor alternativa empregar o CCB. Apesar de considerarem que ambos podem apresentar riscos de contaminação, julgaram que uma redução da concentração de CCA na madeira poderia torná-lo ineficaz e que o CCB possui a desvantagem de ser mais disponível, por exemplo, para lixiviação, porém não seria um problema já que a madeira não estaria exposta à chuva e ao solo. Além disso, sua menor toxicidade em relação ao CCA foi considerada determinante.

Em CIP4 e CIP5, existia um aluno que defendia o uso da madeira plástica, solução que prevaleceu em ambas as duplas após a discussão. Estas consideraram que os blocos poliméricos equivalentes à madeira não possuíam qualquer toxicidade, possuíam propriedades físicas similares à madeira convencional, o que permite que seja trabalhada pelos mesmos carpinteiros acostumados a ela, e ainda possibilitam, em sua produção, a reciclagem de sacolas e embalagens plásticas. Esse conjunto de argumentos direcionou as duas duplas a indicar como solução o emprego desse tipo de material para a casa de Cipreste.

\section{Aprofundamento e amplitude da discussão}

Para avaliação da amplitude e do aprofundamento da discussão, classificamos as mensagens de acordo com o Rainbow. A Figura 4 apresenta o percentual de mensagens classificadas de acordo com o referido quadro.

Ressaltamos na Figura 4 a inexistência de mensagens relacionadas a ações totalmente desvinculadas da tarefa prescrita pelo professor (1). Nas categorias que contemplam aspectos sociais (2 e 3), apenas duas duplas apresentarem mensagens, sendo CIP4 com 7,7\% de mensagens na categoria 2 e CIP5 com 13,3\% na categoria 3. Essas duas duplas não tiveram mensagens classificadas na categoria de organização da tarefa

Tabela 3. Visão inicial de cada membro dos grupos, organização dos grupos e total de mensagens produzidas.

\begin{tabular}{cccc}
\hline Dupla & Abordagem do aluno 1 & Abordagem do aluno 2 & Total de mensagens \\
\hline CIP1 & Solução: CCA & Solução: CCB & 10 \\
CIP2 & Solução: CCA & Solução: CCB & 14 \\
CIP3 & Solução: CCA & Solução: CCB & 15 \\
CIP4 & Solução: CCA & Solução: Madeira plástica & 13 \\
CIP5 & Solução: CCB & Solução: Madeira plástica & 15 \\
\hline
\end{tabular}




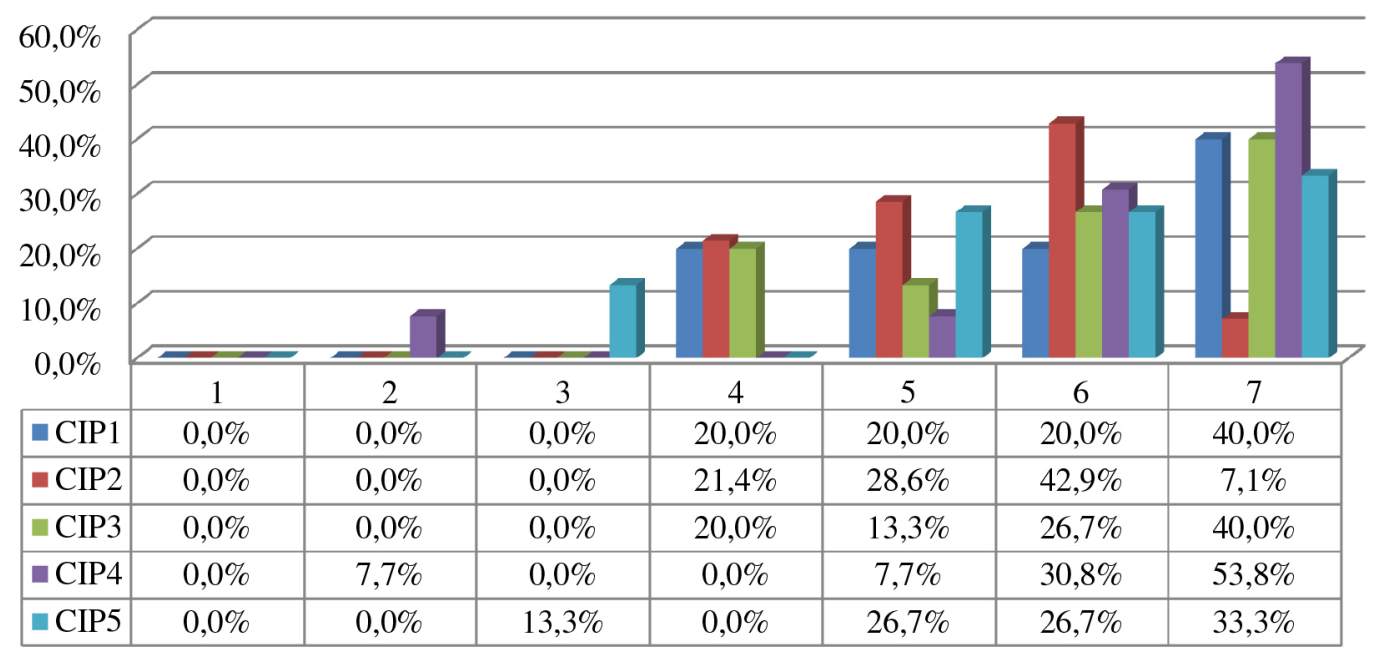

Figura 4. Percentual de mensagens classificadas quanto ao quadro analítico Rainbow.

(4), diferentemente das outras três, que tiveram classificadas, em média, 20\% das mensagens nessa categoria. Dessa forma, com exceção das categorias 2 e 3 nas mensagens de CIP4 e CIP5 e da categoria 4 nas mensagens de CIP1, CIP2 e CIP3, restam entre $78,6 \%$ e $92,3 \%$ de mensagens exclusivamente nas categorias de cunho argumentativo (5-7) nas discussões de cada grupo, o que evidencia o predomínio das mensagens com tal caráter. Entretanto, há diferenças quanto à distribuição das mensagens de conteúdo argumentativo entre as três categorias que expressam esse teor. Em CIP1, CIP3 e CIP4, as mensagens na categoria 7 representam, no mínimo, a metade das mensagens argumentativas. Em CIP5, o percentual de mensagens na categoria 7 representa aproximadamente um terço de todas as mensagens da discussão da dupla, mas é um percentual inferior à soma daqueles apresentados nas categorias 5 e 6 . Por fim, CIP2 obteve apenas 7,1\% de mensagens na categoria de mais elevada utilização de argumentos.

Ao considerarmos os critérios postos no início desta seção para definir uma discussão como satisfatória ou não quanto à produção argumentativa, é possível observar que CIP1, CIP3, CIP4 e CIP5 alcançaram o mínimo de 80\% de mensagens nas categorias 5-7, porém CIP5 não atingiu o mínimo de 40\% na categoria 7. Da mesma forma, CIP2 não atingiu esse mínimo percentual estabelecido na categoria 7 , assim como também não atingiu o mínimo de $80 \%$ nas categorias 5-7, embora tenha se aproximado com 78,6\%. Nessa perspectiva, CIP2 e CIP5 foram consideradas de discussão regular, ao passo que as demais duplas como satisfatórias.

Inicialmente a Figura 4 indicou que quatro duplas haviam se destacado na produção de mensagens com conteúdo argumentativo. Contudo, ao observamos restritamente a categoria 7 , que indica mensagens que exploram e aprofundam as relações entre vários argumentos e contra-argumentos, apenas CIP1, CIP3 e CIP4 mantiveram o destaque com relação à produção desse tipo de mensagens. Para melhor avaliarmos as discussões, é necessário inserir a análise quanto a aprofundamento (níveis 1-4) e amplitude (natureza) referente a cada mensagem argumentativa (5-7).

Ilustramos na Figura 5 um exemplar de como a análise foi realizada. Focalizamos uma única mensagem completa da aluna que defendia a manutenção do uso do CCA em vez da madeira plástica em CIP4. Esta, classificada no Rainbow como 7, foi dividida em quatro parágrafos para melhor demonstrar como ela fez o aprofundamento dos seus argumentos, atingindo os quatro níveis na mesma mensagem. Cabe destacar que tanto a amplitude quanto o aprofundamento podem ter uma ou mais ocorrências na mesma mensagem. No exemplo da Figura 5, foram utilizados quatro argumentos: dois de natureza ambiental e dois de natureza econômica. O referido procedimento de classificação, juntamente com o apresentado na Tabela 2, foi utilizado para analisar as mensagens de caráter argumentativo (5-7) quanto ao aprofundamento da argumentação nelas envolvida (níveis 1-4) e quanto à sua amplitude (natureza).

A Figura 6 apresenta o percentual de mensagens classificadas quanto ao aprofundamento observado nas discussões de cada uma das duplas e indica a existência de semelhanças na distribuição percentual dos níveis de aprofundamento entre elas, destacando-se as semelhanças entre CIP2, CIP3 e CIP5 e, de mesma forma, entre CIP1 e CIP4. Em CIP2, CIP3 e CIP5, houve entre $15,4 \%$ e $21,1 \%$ de mensagens argumentativas de aprofundamento 1 . No outro extremo, essas duplas apresentaram entre $15,4 \%$ e $17,6 \%$ das mensagens argumentativas no nível de aprofundamento 4 . As categorias que representam os níveis 2 e 3, intermediários, ficaram entre $63,2 \%$ e 69,3\% das mensagens. O outro perfil destacado de distribuição percentual das categorias de aprofundamento diz respeito a CIP1 e CIP4. Elas se diferenciam das três anteriores principalmente pelo maior percentual de mensagens na categoria 4 , tendo obtido CIP1 aproximadamente um terço das mensagens nessa categoria e CIP4, 27,3\%.

Os percentuais observados na Figura 6 - ao serem confrontados com o mínimo estabelecido na presente seção para 


\begin{tabular}{|c|c|}
\hline $\begin{array}{l}\text { Considerando a possibilidade de sugerir que a madeireira } \\
\text { passasse a vender a madeira plástica, temos que pensar } \\
\text { na relação custo-benefício. } \\
\text { Apesar de ao se reciclar o plástico se economizar energia } \\
\text { e matéria-prima proveniente do petróleo, que é uma fonte } \\
\text { não renovável, a coleta seletiva requer investimento. O } \\
\text { custo médio dessa coleta representa aproximadamente } \\
\text { dez vezes o preço da coleta convencional. } \\
\text { Um dos motivos para isso acontecer é porque o } \\
\text { caminhão seletivo não pode compactar o lixo da mesma } \\
\text { forma, pois tem que ter compartimentos separados para } \\
\text { cada tipo de material, portanto, cabe menos lixo. } \\
\text { O preço da madeira plástica no mercado devido a tais } \\
\text { condições acaba sendo mais elevado e equivale ao da } \\
\text { madeira nobre. }\end{array}$ & 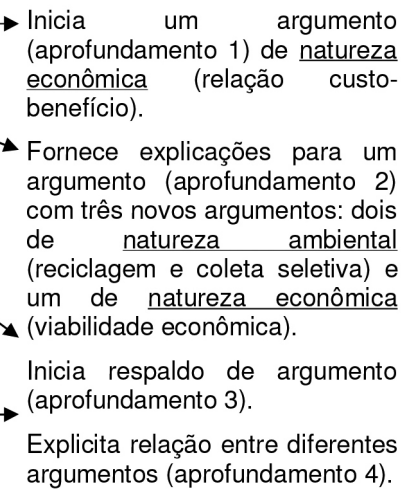 \\
\hline
\end{tabular}

Figura 5. Exemplo de classificação de mensagem quanto ao aprofundamento e à amplitude.

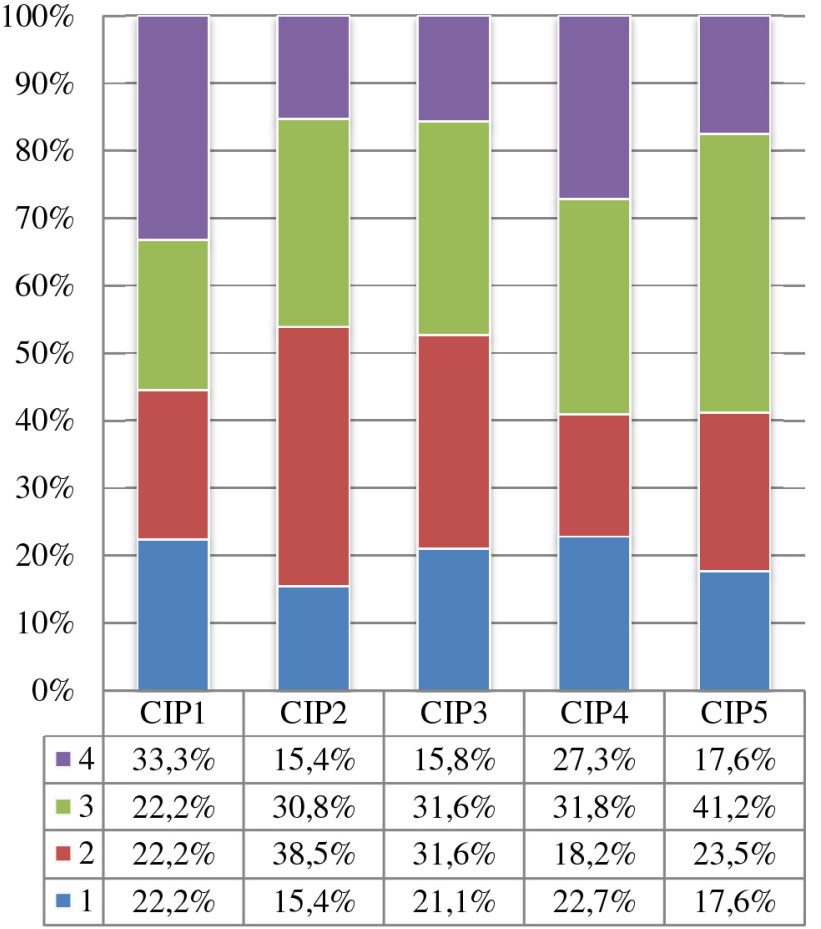

Figura 6. Percentual de mensagens classificadas quanto ao aprofundamento da discussão.

classificar as discussões, quanto ao seu aprofundamento, como satisfatórias ou não - demonstram que apenas CIP1, CIP4 e CIP5 podem ser classificadas como satisfatórias, já que ultrapassaram os $50 \%$ de mensagens argumentativas nas duas categorias de maior aprofundamento. Respectivamente, os percentuais obtidos foram $55,5 \%, 59,1 \%$ e $58,8 \%$. As outras duplas tiveram em torno de $47 \%$ das mensagens nas categorias 3 e 4, mostrando que apesar de serem consideradas insatisfatórias do ponto de vista do aprofundamento dos argumentos, não se distanciaram significativamente. Das três duplas que tiveram suas discussões consideradas satisfatórias pelo Rainbow, apenas CIP1 e CIP4 também tiveram classificado como satisfatório o aprofundamento da discussão. CIP3, considerada satisfatória anteriormente, agora foi classificada como insatisfatória com relação ao aprofundamento das mensagens argumentativas. CIP5 foi considerada como regular pelo Rainbow, mas quanto ao aprofundamento, foi considerada satisfatória. Por último, CIP2 foi considerada regular anteriormente e agora insatisfatória.

No sentido de complementar a discussão desse estudo de caso, a Figura 7 apresenta o percentual de mensagens classificadas quanto à amplitude da discussão (natureza dos argumentos) observada em cada um dos grupos. As mensagens foram classificadas em: científica, econômica, tecnológica, ambiental, social, saúde e política.

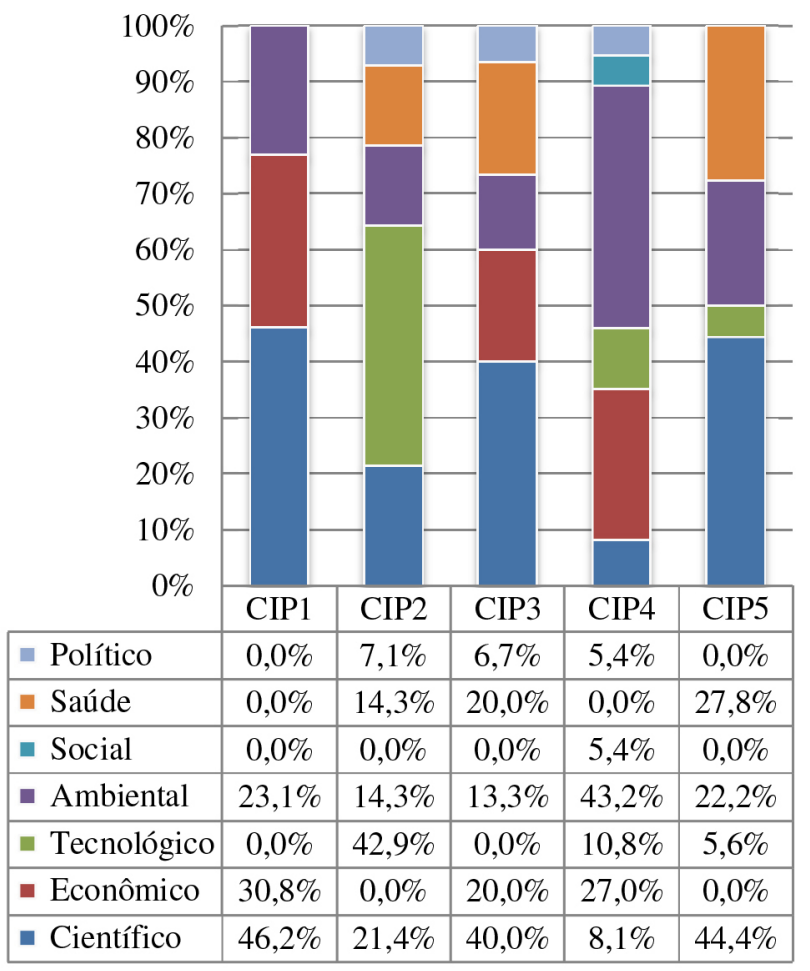

Figura 7. Percentual de mensagens classificadas quanto à amplitude (natureza) dos argumentos.

A análise da Figura 7 permite verificar que nenhuma dupla abordou todas as naturezas de argumentos identificados. CIP4 não incluiu argumentos relacionados a tópicos de saúde. CIP2 não considerou os de natureza social e econômica. Essas duas naturezas somadas a de aspectos políticos não foram incluídas 
na discussão de CIP5. CIP3 não considerou apenas os aspectos de natureza social e tecnológica. Já CIP1 utilizou argumentos de apenas três diferentes naturezas: ambiental, econômica e científica. Com exceção de CIP4, todas as demais duplas tiveram entre 50 e $77 \%$ de argumentos com abordagem científica, econômica ou tecnológica, sendo que CIP2 e CIP5 não tiveram qualquer argumento de natureza econômica, e CIP1 e CIP3, de natureza tecnológica. No entanto, todos apresentaram argumentos de natureza científica e ambiental. CIP1 apresentou a menor variedade de argumento: apenas ambientais, econômicos e científicos. Em oposição, de todos os tipos de argumentos identificados, CIP4 não abordou somente aquele pertinente a tópico de saúde.

A alta diversidade de argumentos produzidos pelos alunos indica que o caso investigativo cumpriu o papel de fomentar a discussão de assuntos de natureza científica e sociocientífica a partir da questão nele embutida: material a ser usado no telhado da casa de Cipreste. A média de diferentes naturezas de argumentos por discussão, conforme observado na Figura 7, é 4,6. Assim, em função dos critérios estabelecidos para apontar a discussão como satisfatória ou não com relação ao uso de diferentes naturezas de argumentos, somente as discussões de CIP2, CIP3 e CIP4 podem ser consideradas satisfatórias por superarem essa média: as duas primeiras com cinco diferentes naturezas, e a última, com seis. CIP1 e CIP5 abarcaram, respectivamente, três e quatro diferentes naturezas de argumento e foram consideradas insatisfatórias quanto à amplitude da discussão.

Ao reunirmos as informações já apresentadas, após a análise com base no Rainbow e no aprofundamento e na amplitude da discussão, verificamos que CIP1, CIP3 e CIP4 se destacaram na produção de argumentos, sendo as únicas classificadas como satisfatórias. No entanto, quando consideradas as demais análises, CIP1 foi satisfatória quanto ao aprofundamento da discussão e não satisfatória quanto à amplitude. $\mathrm{O}$ inverso ocorreu com a discussão de CIP3. Já CIP4 teve sua discussão considerada satisfatória em ambas as análises. Entre as duplas consideradas de produção argumentativa regular, CIP2 e CIP5, a primeira ainda foi considerada insatisfatória quanto ao aprofundamento, e a segunda, quanto à amplitude. Apenas CIP4 teve sua discussão satisfatória sob todos os aspectos analisados. É significativo observar que nenhuma dupla foi considerada insatisfatória sob todos os aspectos, sendo possível afirmar que a resolução do caso permitiu a produção argumentativa dos alunos nas discussões. No entanto, com exceção de CIP4, as discussões ou iniciaram argumentos de várias naturezas (alta amplitude), mas não se aprofundaram adequadamente (baixo aprofundamento), ou não abarcaram diversas naturezas de argumento (baixa amplitude), mas se aprofundaram satisfatoriamente nas naturezas abarcadas (alto aprofundamento).

\section{Qualidade de fundamentos e qualidade conceitual}

Para avaliação da qualidade dos fundamentos e qualidade conceitual, classificamos as mensagens de acordo com o quadro analítico proposto por Clark e Sampson (2008). A distribuição percentual da classificação das mensagens pelas 11 categorias do referido quadro para cada uma das duplas é apresentada na Figura 8.

A análise da Figura 8 revela que não ocorreram mensagens fora da tarefa prescrita pelo professor (1). Nas outras duas categorias que não expressam conteúdo argumentativo, a categoria organização da participação (2) apareceu nas discussões de três das cinco duplas com percentuais entre 6,7\% e 13,3\%. Entretanto, a outra categoria que não expressa conteúdos argumentativos, a de consulta sobre o significado (3), teve considerável presença nas discussões, variando de $14,3 \%$ a $20 \%$ em quatro das cinco duplas. Apenas CIP5 não teve mensagens classificadas nessa categoria. Nas demais oito categorias de movimento discursivo, as que denotam conteúdo argumentativo (4-11), a única constatada nas discussões de todas as cinco duplas foi a de enunciação de argumentos (11), embora apenas CIP5 tenha ultrapassado os $10 \%$ de mensagens assim classificadas. As categorias argumentativas que prevaleceram nas discussões foram a de respaldo de um argumento (6) e a de esclarecimento de um significado (4), sendo que a primeira não apareceu na discussão de CIP1, e a segunda, na de CIP5. Ainda assim, os percentuais apresentados nessas categorias, somados, representam de $40 \%$ a 53,3\% das mensagens de CIP1, CIP2, CIP3 e CIP5. Apenas em CIP4 a soma dessas categorias não alcançou os $40 \%$, ficando em 30,8\% do total das mensagens da discussão. Das oito categorias de mensagens argumentativas, CIP1 e CIP3 não abordaram duas, sendo uma delas a refutação contra fundamentos (9). CIP2 e CIP4 não abordaram apenas uma delas, a contra-argumentação (10). Já CIP5 tratou de apenas três das oito categorias.

Entre as categorias não argumentativas, predominaram as consultas sobre significados (3), já entre as categorias argumentativas, predominaram os esclarecimentos de significado (4) e respaldos (6). Isso mostra que, de forma geral, as discussões se concentraram na apresentação de poucos argumentos e contra-argumentos que foram iniciados e seguidos pela inserção de diversos respaldos e de perguntas sobre o significado de alguma parte da solução do caso e de respectivos esclarecimentos. Assim, categorias fundamentais para a discussão, como enunciação de argumento (11), contra-argumento (10), refutações (8) e mudança de argumento (7), não foram enfatizadas.

No início da presente seção, estabelecemos o mínimo de $80 \%$ das mensagens de caráter argumentativo para a discussão ser considerada satisfatória. Além disso, definimos como regular toda discussão compreendida entre $40 \%$ e $79 \%$ e abaixo de $40 \%$ como insatisfatória. Com base nesses critérios, observamos que apenas CIP1, CIP2 e CIP5 podem ser consideradas como de discussão satisfatória, já que tiveram, respectivamente, $80 \%, 85,5 \%$ e $86,6 \%$ de mensagens classificadas nas categorias argumentativas. CIP3 com 73,5\% e CIP4 com 77\% foram consideradas como de produção argumentativa regular.

Fica evidenciada, portanto, a significativa presença de 


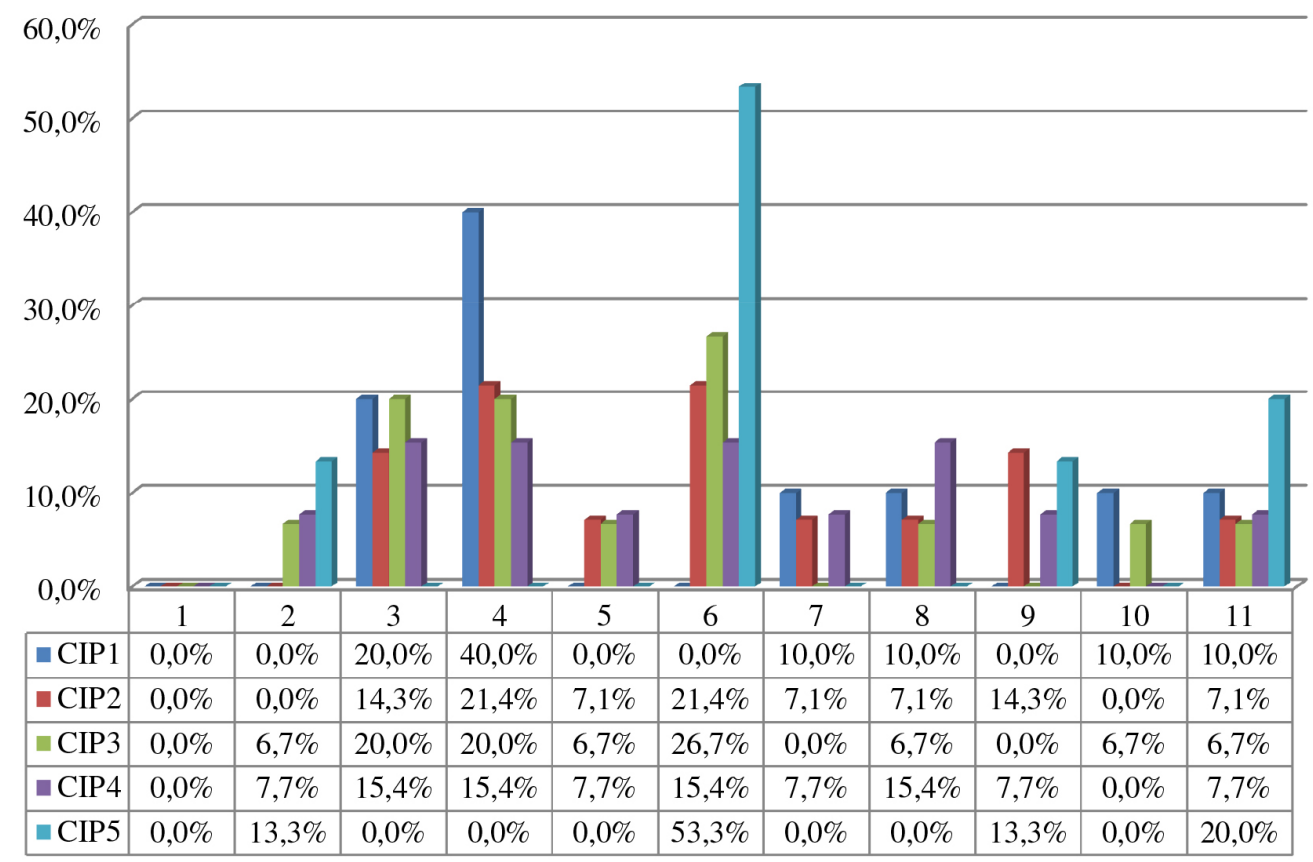
1. Fora da tarefa
2. Organização da participação
3. Consulta sobre o significado
4. Esclarecimento de um significado
5. Esclarecimento em resposta a uma refutação
6. Respaldo de um argumento

7. Mudança de argumento

8. Refutação contra tese

9. Refutação contra fundamentos

10. Contra-argumentação

11. Enunciação de argumento

Figura 8. Percentual de mensagens classificadas quanto aos movimentos discursivos.

mensagens em categorias não argumentativas nas discussões do caso investigativo. Os percentuais de mensagens nessas categorias contribuíram para que duas discussões não fossem consideradas satisfatórias e para que uma terceira conseguisse alcançar o mínimo esperado de mensagens argumentativas no limite dos $80 \%$ definidos. Essa produção de mensagens não argumentativas fez com que importantes categorias de cunho argumentativo fossem pouco exploradas ou mesmo nem integrassem algumas discussões. $\mathrm{O}$ aspecto positivo que se destaca é o fato de, com exceção de CIP5, as demais conseguirem distribuir bem suas mensagens argumentativas por várias categorias, mesmo que com percentuais pequenos em cada uma delas. Assim, para melhor compreendermos essas análises, consideramos a qualidade de fundamentos e a qualidade conceitual das mensagens que expressam conteúdo argumentativo.

A Figura 9 apresenta o percentual de mensagens classificadas quanto à qualidade dos fundamentos das mensagens argumentativas presentes nas discussões de cada uma das duplas.

A Figura 9 ilustra o predomínio de mensagens classificadas como nível de qualidade de fundamentos 0 . Com exceção de CIP4, que teve pouco menos de $20 \%$ de mensagens nessa categoria, os demais tiveram pelo menos um terço das mensagens assim classificadas, alcançando até $60 \%$ em CIP2 e ultrapassando essa marca em CIP5. Isso mostra que nestas duplas majoritariamente, as mensagens não incluíam justificativas no posicionamento dos alunos ou possuíam, mas apenas a partir da reescrita de textos já expostos ou do uso de informações sem

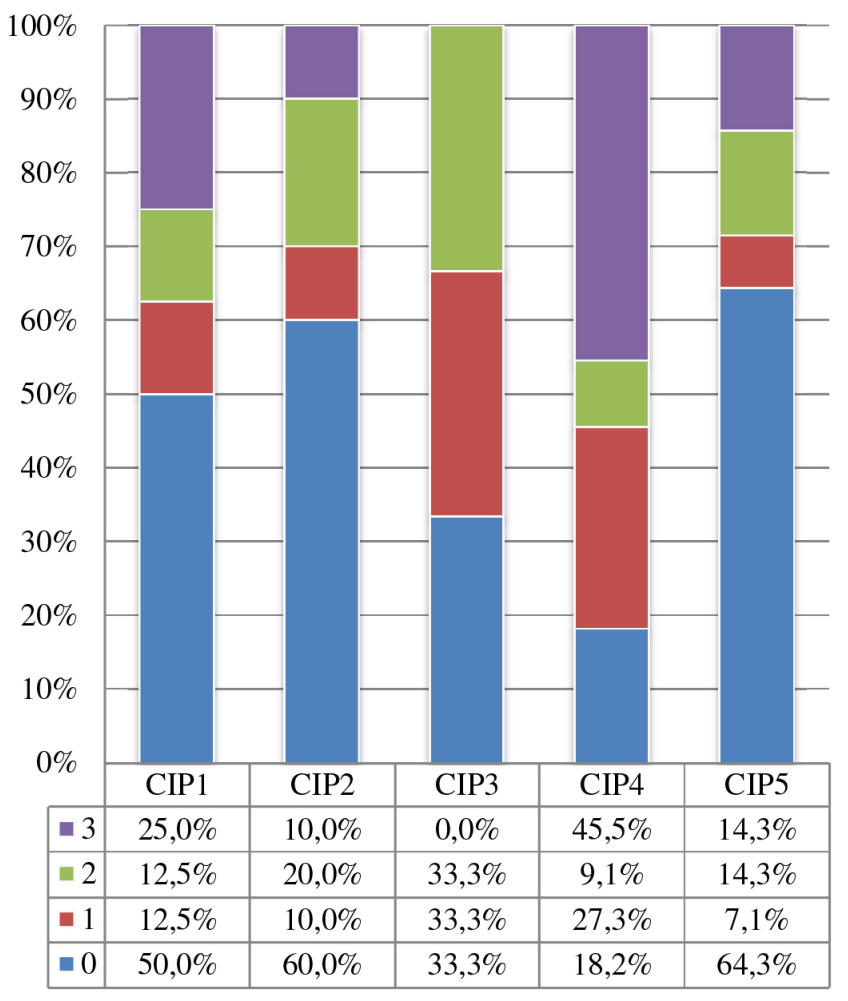

Figura 9. Percentual de mensagens classificadas quanto aos níveis de qualidade dos fundamentos.

relevância ou baseadas em obviedades. No outro extremo, as mensagens com nível de qualidade de fundamentos 3 , ou seja, 
que coordenam múltiplas fontes de evidências, foram recorrentes em CIP4, com 45,5\% das mensagens da discussão, e CIP1, com 25\%. CIP2 e CIP5 tiveram somente $10 \%$ e $14,3 \%$, respectivamente, de mensagens nesse nível, enquanto que CIP3 não teve nenhuma mensagem assim classificada.

Nos níveis intermediários de qualidade de fundamentos 1 e 2, destacou-se CIP3, que não apresentou mensagens no nível 3. Esta teve dois terços das mensagens nos dois níveis intermediários, enquanto as demais oscilaram entre $21,4 \%$ e $36,4 \%$ da discussão nos níveis intermediários. Nessa perspectiva, CIP1, CIP2 e CIP5 se destacam com pelo menos a metade das mensagens concentradas no nível 0 e de $7,1 \%$ a $25 \%$ em cada uma das três demais categorias. Já CIP3 não teve nenhuma mensagem classificada como nível de qualidade de fundamentos $3 \mathrm{e}$ demonstrou distribuição equitativa nas três outras categorias. Por último, na discussão de CIP4, predominaram mensagens com nível de qualidade de fundamentos 3 . Inicialmente definimos o mínimo da metade das mensagens da discussão nas categorias 2 e 3 para considerá-la como satisfatória. Contudo, observamos que, com exceção de CIP4, as demais tiveram, no mínimo, 62,5\% das mensagens nas categorias que representam os níveis 0 e 1 . Mesmo CIP4 teve 45,5\% nessas categorias. De maneira complementar, vemos que CIP4 teve $54,6 \%$ de mensagens nos níveis de qualidade de fundamentos mais elevados, sendo a única a ser considerada satisfatória sobre esse aspecto. As demais, no máximo, alcançaram 37,5\% nos níveis 2 e 3 , sendo, portanto, consideradas insatisfatórias.

A seguinte especulação pode ser feita com base na classificação dos movimentos discursivos da Figura 8: quando houve predomínio de mensagens de respaldo entre aquelas com conteúdo argumentativo, é possível que tenham ocorrido várias mensagens de respaldo a uma argumentação enunciada previamente com afirmações sem grande relevância ou repetitivas e sem qualidade de fundamentos adequada. Mesmo não sendo possível desprezar os percentuais de mensagens com altos níveis de qualidade de fundamentos, isto é, em torno de $55 \%$ de mensagens classificadas como níveis 2 e 3 em CIP4 e algo em torno de $32 \%$ nas demais duplas, os dados nos permitem construir o entendimento de que não houve adequada preocupação dos alunos em estruturar seus argumentos e utilizar diversas fontes de evidências.

Para concluirmos a análise até aqui apresentada sobre o caso investigativo, é necessário considerarmos também a qualidade conceitual das mensagens. Assim, na Figura 10, apresentamos a distribuição percentual da classificação das mensagens quanto à sua qualidade conceitual.

Na Figura 10, duas informações se destacam. Inicialmente frisamos que não houve qualquer mensagem no nível de qualidade conceitual 0, não normativa. Em seguida, cabe ressaltar que somente CIP4 e CIP5 apresentaram mensagens no nível 3 , multinormativo: a primeira dupla com $33,3 \%$, e a segunda, com 37,5\%. Dessa forma, CIP1, CIP2 e CIP3 tiveram todas as suas mensagens científicas nos níveis intermediários 1

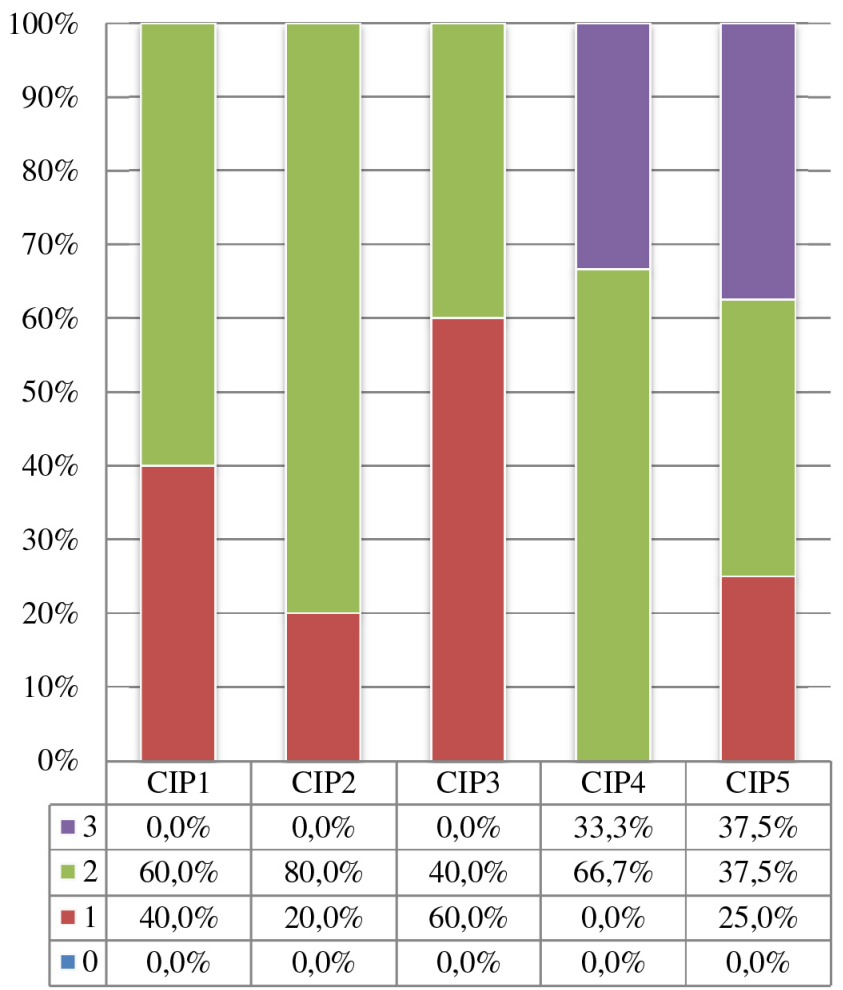

Figura 10. Percentual de mensagens classificadas quanto aos níveis de qualidade conceitual.

(transitório) e 2 (normativo). Esses dois níveis foram responsáveis pela classificação de $66,7 \%$ e $62,5 \%$ das discussões de CIP4 e CIP5, respectivamente. Inicialmente definimos o mínimo da metade das mensagens nos dois níveis mais elevados, 2 e 3, para a discussão ser considerada satisfatória quanto à qualidade conceitual. Observando os percentuais alcançados, vemos que somente CIP3 não atingiu esse mínimo, pois teve somente $40 \%$ de mensagens no nível 2 e nenhuma no nível 3 , sendo assim considerada insatisfatória. As discussões de CIP1 e CIP2 foram consideradas como de qualidade conceitual satisfatória por terem atingido, respectivamente, $60 \%$ e $80 \%$, percentuais obtidos exclusivamente no nível 2. As discussões de CIP4 e CIP5 também foram consideradas satisfatórias, mas por terem alcançado, respectivamente, $100 \%$ e $75 \%$ nos níveis 2 e 3 . Observa-se, portanto, a significativa maior qualidade dos argumentos dessas duplas, especialmente de CIP4, em relação às demais.

Embora durante as discussões os alunos tenham concentrado suas mensagens argumentativas em poucas categorias relacionadas aos movimentos discursivos, especialmente a de respaldo, e apesar de cerca de dois terços das mensagens possuírem qualidade dos fundamentos da argumentação no nível 0 e 1, majoritariamente os argumentos científicos foram normativos. Estes, embora coerentes com princípios científicos, foram apresentados sem maior aprofundamento dos fundamentos da argumentação, verificando-se baixa utilização de mensagens que exigem maior grau dessa prática como contra-argumentação e refutação. 
Com relação aos dados dessa análise, a discussão de CIP4 foi a única a atender o mínimo esperado de mensagens nas categorias 2 e 3 de qualidade de fundamentos da discussão. Além disso, $100 \%$ dos argumentos científicos de CIP4 estiveram nos níveis 2 e 3 de qualidade conceitual. Tais constatações credenciam essa dupla como a que melhor desenvolveu a argumentação para solucionar o caso investigativo, mesmo tendo sua discussão sido considerada regular com relação aos movimentos discursivos. As demais discussões, com exceção de CIP3, equivalem-se, uma vez que todas foram consideradas satisfatórias quanto aos movimentos discursivos. Todas foram insatisfatórias com relação à qualidade de fundamentos e foram satisfatórias na qualidade conceitual. Já CIP3 foi regular quanto à produção de argumentos com relação aos movimentos discursivos e não satisfatória na qualidade de fundamentos e conceitual, o que a caracteriza como a menos eficiente entre as demais.

\section{Considerações Finais}

Neste trabalho, investigamos uma atividade didática, pautada na resolução de um caso investigativo, ocorrida no fórum do ambiente virtual de ensino-aprendizagem eduqui. info, com graduandos em química. De posse das mensagens produzidas no fórum, analisamos as interações entre duplas de alunos em cada discussão a partir da classificação destas. Dessa forma, foi possível apontar em que medida os alunos se engajaram nas atividades argumentativas, assim como avaliar o aprofundamento e a amplitude das mensagens, os movimentos discursivos empreendidos na sua construção e a qualidade dos seus fundamentos. As mensagens de conteúdo argumentativo foram ainda analisadas quanto à qualidade conceitual. Duas questões guiaram o trabalho, uma investigava em que medida as atividades didáticas apresentadas no fórum do eduqui.info favoreciam a prática da argumentação; e a outra indagava sobre qual a qualidade dos argumentos produzidos pelos alunos a partir da realização de tais atividades.

Com relação à primeira questão, é possível afirmar que as práticas argumentativas foram substancialmente fomentadas no contexto didático delineado. De fato, a maior parte das mensagens veiculadas no fórum possui cunho argumentativo, nenhuma delas se relaciona a ações totalmente desvinculadas da tarefa prescrita pelo professor e poucas contemplam aspectos sociais ou vinculados à organização da atividade.

No que concerne à segunda questão, é notável a diversidade da natureza dos argumentos produzidos pelos alunos, corroborando a potencialidade do uso do estudo de caso no estímulo à discussão de assuntos de natureza científica e sociocientífica. No entanto, considerando a avaliação da qualidade conceitual e de fundamentos, observamos que apesar da qualidade dos fundamentos da discussão ter ficado abaixo do esperado, a qualidade conceitual se destacou positivamente com elevado uso de argumentos normativos e multinormativos, o que sugere que o estudo de caso fomentou o emprego e a discussão de argumentos coerentes com a linguagem científica e com as teorias em pauta.

Diante das tessituras efetuadas, é possível depreender a adequação do uso de estudo de casos como desencadeador de práticas argumentativas tanto em salas de aula, nas quais os alunos estabelecem uma interação face a face, quanto em ambientes virtuais de ensino-aprendizagem. Nessa perspectiva, o presente trabalho traz elementos que podem vir a colaborar com a difusão do método nos diversos níveis de ensino e com a realização de novas investigações sobre as suas potencialidades no ensino de ciências.

\section{Referências}

AMELSVOORT, M.V.; ANDRIESSEN, J.; KANSELAAR, G. Representational tools in computer-supported collaborative argumentation-based learning: how dyads work with constructed and inspected argumentative diagrams. The Journal of the Learning Science, v. 16, n. 4, p. 485-521, 2007.

BAKER, M.; ANDRIESSEN, J.; LUND, K; AMELSVOORT, M.; QUIGNARD, M. Rainbow: a framework for analyzing computermediated pedagogical debates. Computer-Supported Collaborative Learning, v. 2, p. 315-357, 2007.

BRITO, J.Q.A; SÁ, L.P. Estratégias promotoras da argumentação sobre questões sociocientíficas com alunos do ensino médio. Revista Electrónica de Ensenãnza de las Ciencias, v. 9, n. 3, p. 505-529, 2010.

CLARK, D.; SAMPSON, V. Assessing dialogic argumentation in online environments to relate structure, grounds, and conceptual quality. Journal of Research in Science Teaching, v. 45, n. 3, p. 293-321, 2008.

ERDURAN, S.; JIMÉNEZ-ALEIXANDRE, M.P. Argumentation in science education: perspectives from classroom-based research. 35th. New York: Springer, 2008.

GIJLERS, H.; WEINBERGER, A.; DIJK, A.; BOLLEN, L.; JOOLINGEN, W. Collaborative drawing on a shared digital canvas in elementary science education: the effects of script and task awareness support. International Journal of Computer-Supported Collaborative Learning, v. 8, n. 4, p. 427-453, 2013.

HERREID, C. F. Response to: the problem with problem-based medical education: Promises not kept by R. H. Glew. Biochemistry and Molecular Biology Education, v. 32, n. 4, p. 253-254, 2003.

JIMÉNEZ-ALEIXANDRE, M.P. Determinism and underdetermination in genetics: implications for students' engagement in argumentation and epistemic practices. Science \& Education, v. 23, n. 2, p. 465484, 2014.

KIM, I.; ANDERSON, R.C.; NGUYEN-JAHIEL, K.; ARCHODIDOU, A. Discourse patterns during children's collaborative online discussions. Journal of the Learning Sciences, v. 16, n. 3, p. $333-$ 370, 2007.

MUNNEKE, L.; ANDRIESSEN, J.; KANSELAAR, G.; KIRSCNER, P. Supporting interactive argumentation: influence of representational 
tools on discussing a wicked problem. Computers in Human Behavior, v. 23, n. 3, p. 1072-1088, 2007.

PAZINATO, M.S.; BRAIBANTE, M.E.F. O estudo de caso como estratégia metodológica para o ensino de química no nível médio. Revista Ciências \& Ideias, v. 5, n. 2, p. 1- 18, 2014.

QUEIROZ, S.L.; SÁ, L.P. O espaço para a argumentação no ensino superior de química. Educación Química, v. 20, n. 2, p. 104-110, 2009.

SÁ, L.P. Estudo de casos na promoção da argumentação sobre questões sociocientíficas no ensino superior de química. 2010. Tese (Doutorado em Química) - Universidade Federal de São Carlos, São Carlos, 2010.

SÁ, L.P.; FRANCISCO, C.A.; QUEIROZ, S.L. Estudos de caso em química. Química Nova, v. 30, n. 3, p. 731-739, 2007.

SÁ, L.P.; QUEIROZ, S.L. Promovendo a argumentação no ensino superior de química. Química Nova, v. 30, n. 8, p. 2035-2042, 2007.

Estudo de casos no ensino de química. 2. ed. Campinas: Átomo, 2009.

SANTOS, W.L.P. Debate on global warming as a socio-scientific issue: science teaching towards political literacy. Cultural Studies of Science Education, v. 9, n. 3, p. 663-674, 2014.
SCHEUER, O.; LOLL, F.; PINKWART, N.; MCLAREN, B.M. Computer-supported argumentation: a review of the state of the art. International Journal of Computer-Supported Collaborative Learning, v. 5, n. 1, p. 43-102, 2010.

SOUSA, R.S.; ROCHA, P.D.P; GARCIA, I.T.S. Estudo de caso em aula de química: percepção dos estudantes de nível médio sobre o desenvolvimento de suas habilidades. Química Nova na Escola, v. 34, n. 4, p. 220-228, 2012.

SOUZA, N.S.; QUEIROZ, S.L. Gêmeos, genéricos e quirais: um estudo de caso sobre a relação entre estereoquímica e atividade farmacológica. Ensino, Saúde e Ambiente, v. 7, n. 1, Ed. especial, 2014.

STAHL, G.; CRESS, U.; LUDVIGSEN, S.; LAW, N. Dialogic foundations of CSCL. International Journal of Computer-Supported Collaborative Learning, v. 9, n. 2, p. 117-125, 2014.

TOULMIN, S. Os usos do argumento. São Paulo: Martins Fontes, 2001. 